\title{
The Sharp Rejoinder and the Linguistic Repartee: A Linguistic Experimental Study in the Structure Rules
}

\author{
EMAD AHMAD ALZABIN \\ Department of Arabic Language, \\ College of Humanities and Social Sciences, \\ UAE University, United Arab Emirates \\ emadzapin@uaeu.ac.ae
}

\begin{abstract}
This study determines the laws of linguistic structures that cause linguistic shock in sharp rejoinders in an argumentative dialogue. Particularly, this research examines and analyses numerous sharp rejoinders, demonstrates the related laws, divides them into a set of linguistic matrices and explains the systems that cause the sharp rejoinders to assume that understanding these answers will raise the linguistic repartee level in our argumentative conversations. This experimental study used an experimental linguistic approach to explain the laws of these matrices to several students, specifically to show their effects when the linguistic repartee level is raised. Therefore, the current research is bifacial theoretical and experimental in nature. The experimental part showed the students' ability to promptly produce the appropriate responses according to the experimental conditions. Consequently, the importance of studying the rules of linguistic structure was reflected when the linguistic repartee level of recipients is raised.
\end{abstract}

Keywords: Experimental study; Linguistic matrices; Linguistic Repartee; Linguistic Shock; Sharp Rejoinder

\section{INTRODUCTION}

The phenomenon of sharp rejoinders is a significant indicator of the extent to which linguistic repartee is achieved in the argumentative dialogue context. Hence, studying the rules of linguistic structures of these answers will provide us with the guidelines that constitute linguistic repartee and how this will impact on raising the linguistic repartee of speakers during dialogues and debates.

The problem of this study involves showing these rules, laws and internal attachments in sharp rejoinders systems that cause linguistic stroke. Particularly, these attachments and laws are not visible to many users of language. Consequently, this limitation causes the phenomenon of linguistic stroke and disrupts linguistic repartee in the production of appropriate responses.

No previous linguistic research has discussed this issue from an analytical point of view, thereby leading to the study of many of these answers. Three students were asked to collect, study, and analyse samples to show the laws of these samples. After dividing them into a group of linguistic matrices, the students explained systems that cause stroke answers by emphasising that understanding these systems will raise the linguistic repartee level in our argumentative dialogues.

This study's experimental approach used a questionnaire to investigate the impact of understanding the laws on raising the linguistic repartee level of recipients. This process involved identifying the elements and characteristics of sharp rejoinders and attempting to control the pace of the response production. The students' responses were observed over time, and the laws of these linguistic matrices were explained to them. They were provided with additional new sharp rejoinders to observe their improvement rate in producing timely and appropriate responses. This study attempted to reveal the linguistic reasons and elements of the linguistic structure that cause linguistic shock in sharp rejoinders. Accordingly, we would be able to develop language rules that regulate linguistic thinking and raise the 
repartee level in the argumentative dialogues that we practice. These rules can also be developed in the media, where argumentations and debates are central. Other areas can also operationalise these rules in the human social environment. The main result of this study shows that the understanding of these matrix systems raises the linguistic repartee levels of speakers. The development of these rules through successive interdisciplinary studies can produce other results that support the linguistic function of communication within the human community. In this regard I would like to thank my three students: Mariam Harimo, Aisha Al Kaabi, and Wafaa Al Buraiki. They worked hard with me to gather the answers, and help in building, distributing and analyzing the questionnaire.

\section{CONCEPTUAL FRAMEWORK}

The concept of 'linguistic repartee' should firstly be clarified. Although this concept is complex and overlapping, it can be considered a form of supreme intelligence (Henden 2004, 7). 'Repartee' refers to the presence of talent, readiness and instincts that enable us to collect and analyse information immediately and effectively (Dane et al. 2007, p. 33). Thus, repartee is associated with the speed of mental processing performance and significant ability to rapidly and effectively recall required information. If thinking is a structural internal movement in abstractions (Brabandere et al. 2013, p. 7), then repartee is considered a requirement in this movement associated with the factors of speed and effectiveness. Accordingly, repartee can possibly have a psychological, biological and philosophical nature because it is part of intuition (Simone 2014, pp. 13-35). Hence, repartee and intuition can be considered competence, which can exist or be developed in or used by every human being (Gee 1999, p. 3). If the word 'linguistic' is added, then 'linguistic repartee' refers to the ability to produce the appropriate linguistic patterns immediately and effectively. The meaning of 'appropriate' is associated with context and situation; otherwise, it will be merely a voice that does not reflect the real meaning of repartee. If this production process exists in the field of consciousness, then we are convinced that such a process is as rapid as the processes in the unconscious field, such as intuition (Lufityanto et al. 2016, p. 1). Accordingly, the following questions should be answered: What is the meaning of 'like the processes in the unconscious field? The production process is an internal movement characterised by summoning and building. That is, the self recalls separate meanings (sememe) and arranges them according to the intention. However, this process may appear to be in the unconscious field when it is super-fast, which is an ability that can be developed through practice. The faster this process is, the less self-conscious it is.

Thinking is stressful and needs high biological exertion (Dennett 2013, p. 1). This exertion arises in the linguistic process by summoning, arrangement and building, which need biological exertion and time. Hence, 'linguistic repartee' exists between these two sections (=Biological exertion and time), in which incurring biological exertion immediately reflects the real meaning of this concept. In my estimation, the final linguistic product reflects the nonverbal internal concatenations (Lieberman 2000, 111), which is similar to the internal speech' category in the rationalist effort of Muslim scholars (Al-Zabin 2014, 307-325). 


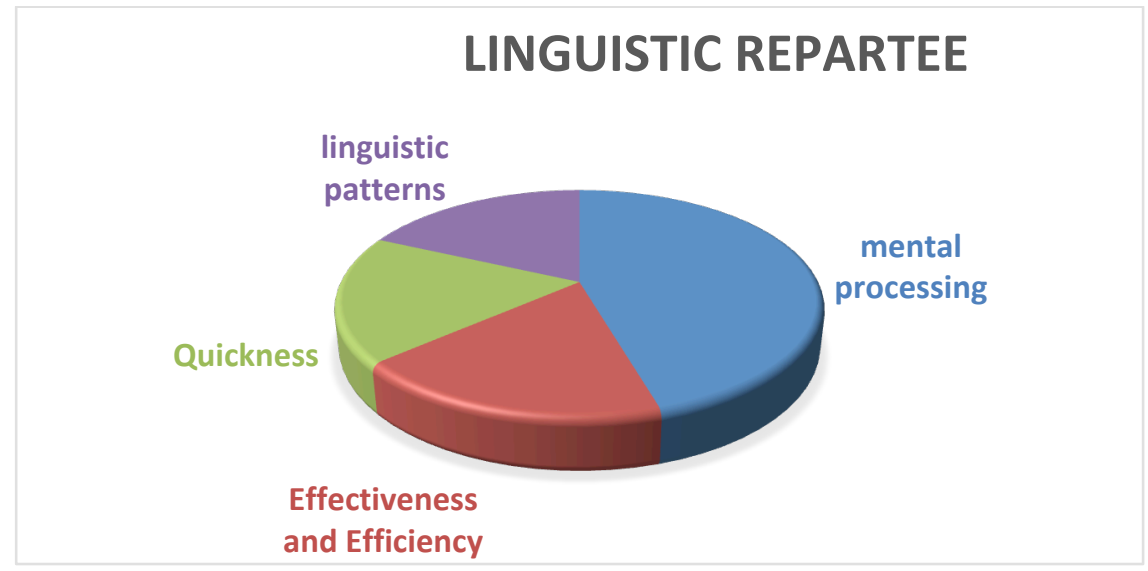

FIGURE 1. Linguistic Repartee

The Kahneman hypothesis states that the mind is operated by two systems (i.e. 1 and 2 ), with each system having its own properties. System (1) works automatically and rapidly and with minimal effort. Control over its work is absent, thereby resulting in weak or missing self-control. System (2) is related to high mental processes that need consideration, effort and analysis. System (1) includes an achieved model of existence. Its response is rapid and immediate, which can occur as soon as a preliminary conception is obtained. System (1) is the source of immediate intuitive judgements, thereby resulting as well in methodological errors in judgements. Amongst the functions of system (2) are to restraint system (1) and reject its whims in immediate response. Moreover, system (2) controls the thinking movement in system (1) (Kahneman 2011). Thus, linguistic repartee raises the competence of system (2), thereby enabling it to work at the speed of system (1) whilst maintaining its properties of impoundment, analysis and investigation. Kahneman's hypothesis enables us to understand linguistic repartee because the mind in this context will work with the properties and speed of systems (2) and (1), respectively. That is, the mind will produce the linguistic matrices that it controls and are under the control of consciousness and result from the consciousness and understanding of the linguistic formation rules. Consequently, linguistic processing is characterised as flexible, rapid and effective. Bandler and Grinder (1975) formulated the 'meta-model for language'. This model of questions assumes the existence of deep and surface structures of speech, in which the deep structure contains substantial details. These details are lost in the speech flow channels from the deep to the surface structure through the strategies of deletion, generalisation, distortion and modeling (Bandler et al. 1975, p. 19). In this case, the roles of linguistic repartee include conducting these processes super-fast and effectively and immediately preparing the conversion models in the language.

TABLE 1. Mind Systems

\begin{tabular}{cc}
\hline System (1) & System (2) \\
\hline Minimal effort and works automatically and rapidly & Deep analysis and is related to high mental processes \\
No control over its work & Controls the thinking movement in system (1) \\
Checks everything and does not include an achieved \\
model of existence
\end{tabular}

Syllogism matrices are defined as linguistic propositions (i.e. sentences) that represent the vanguards of a syndrome that leads to results. These matrices are logical linguistic matrices produced by the condition of congruence and correctness, which is a linguistic unit resulting from congruence. The process of producing these linguistic units is called syllogism (Bornat 2017). The current study used these matrices to elucidate the nonverbal internal 
concatenations in a cognitive scope (See: Hung 2019, p. 115) Thereafter, these matrices are used as tools to reflect the internal hierarchy of the thinking process (i.e. summoning, arranging and building).

\section{PROPERTIES OF THE SHARP REJOINDER}

This study attempts to answer the following basic question: What are the properties of a sharp rejoinder? A 'sharp rejoinder' is a rapid regulatory answer that causes the opponent's silence. Sharp rejoinder leads to linguistic shock. Our thinking works automatically and rapidly and may be distant from the conscious inspection level (Albrecht 1980, p. 25). The lower the conscious inspection level, the higher the probability of linguistic shock and conscious inspection level and the longer the response time. Thus, the response to a sharp rejoinder should be a rapid and effective conscious inspection. This response should also be separated from the actual rejoinder maker and focus on the linguistic matrices in a sharp rejoinder. The reason is that in the majority of our argumentation, we follow others in acceptance and rejection (Elder et al. 2013, p. 97).

Meanwhile, the properties of a sharp rejoinder should be clarified. Matthias (2008) collected and studied many of these properties. The majority of the sharp rejoinders are crafted in a cheerful style and hardly reflect a painful and veiled response, with no apparent hostility. These sharp rejoinders are also unexpected. Moreover, a sharp rejoinder is a linguistic entity that does not exist within the ambit of expectation. The greater the surprise, the greater the impact. The sharp rejoinder is characterised by novelty and is typically unusual. However, the sharp rejoinder must be clearly understood to achieve impact. However, one of the elements of a sharp rejoinder is that the message is not disclosed clearly, and a gap, which is not considerably long, should be provided for thinking. That is, understanding a sharp rejoinder requires a simple mental exertion. Matthias Pöhm called this motivational gap a 'non-enclosed bow'. The motivational gap rule affects the strength of a sharp rejoinder. That is, the greater the motivational gap, the greater the effects of the sharp rejoinder, unless it does not become substantially complicated. If anyone says to another that 'Your face is pale today', the latter may answer, 'You, yourself look pale today'. This response is not considered a sharp rejoinder because the gap that the opponent has to fill in has not widened. However, if the answer is 'Thank God that there is no mirror in the house', then it would have been a sharp rejoinder (Matthias 2008, pp. 26-28).

An important question should be asked about the qualities of a sharp rejoinder maker. His most important qualities include his readiness for verbal attack, in the sense that he is not timid, fearful or sensitive. Moreover, he is extremely knowledgeable and has the ability to penetrate the postulates fence immediately (De bono 1967, 12). He can process the subjects rapidly and efficiently, and has a deep understanding of things, attitudes and people. He also has an overactive imagination. Additionally, he is frank and handles things calmly, neatly and rapidly (Chambers et al. 1833, p. 369). Consequently, he possesses the ability and talent to perform intellectual movements (i.e. thinking) immediately and effectively.

Meanwhile, the following question should be answered: How does a sharp rejoinder cause a linguistic shock? A sharp rejoinder is a structured linguistic entity that reflects complex intellectual arrangements. Listeners' responses require comprehension, rearrangement of meanings (i.e. thought), and composition. Moreover, the rearrangement of meanings requires an internal organised movement within the abstract units. Thus, a sharp rejoinder is a logical matrix of propositions that disrupts the internal self-arrangement with a recipient. That is, a sharp rejoinder impairs the process of thinking on which the construction of linguistic units is based. Evidently, these units are the complete product that is the 
response of a sharp rejoinder, as well as to the factors of speed, surprise and unpredictability. Therefore, recipients may conjure appropriate answers after all these obstacles have passed. However, eliminating the obstacles may take a long time, after which the response will not be important. Additionally, we should discuss the issue of 'priming effect', which means hearing a word that can cause a wave of instant measurable changes, and occurs by summoning a wave of words belonging to the situation (Kahneman 2011). This recall process occurs through the brain, which rapidly summons the semantic and lexical connections in the different semantic fields in the linguistic memory storage. The assumption is that the logical matrices of the linguistic sentences in a sharp rejoinder are able to disrupt the priming effect in the brain. Consequently, a temporary trance occurs in the analytical system (2), thereby causing a linguistic shock. The linguistic units are divided into two parts: affirmative, which exists outside of the self, and the nature is either audible or visible material; and internal, which exists within the self, and not of a material nature but in the form of abstract propositions). A parallel linguistic entity also exists within the self-based on intellectual arrangement (i.e. meanings), which is the affirmative existence of speech. Thus, if this parallel linguistic entity is disrupted, a disruption in the production of affirmative linguistic units will definitely follow (Al-Zabin 2018, 15).

Therefore, I propose to classify linguistic shock in the schedule of accidental language disorders, which affects human organs for a specific time owing to accidental factors. This case is similar to that of non-chronic epilepsy, and an irregularity of intellectual routes in the brain. Consequently, the ability to produce affirmative linguistic sentences is disrupted, thereby leading to the occurrence of linguistic shock. The current study can lead to neurolinguistics and brain function studies to characterise the issue in a biological manner based on experimental studies.

The elements of this thesis should be determined through the experience of the syllogism matrices power in a sharp rejoinder. Given my intention to follow the conditions of the appropriate method in my study, the manipulation of linguistic shock requires insights from many disciplines. Hence, I will pursue my study by using the experience of the syllogism matrices. In the next subsection, I will propose a solution for linguistic shock using the analytical descriptive and experimental methods.

\section{SYSTEMS OF SYLLOGISM MATRICES AND THEIR EFFECTS ON RAISING THE LINGUISTIC REPARTEE LEVEL}

This study uses structural analysis of a sharp rejoinder and comprises the discussion of the laws of structure in these responses using the descriptive and analytical methods. Accordingly, the following essential issues should be addressed:

1. studying a sharp rejoinder to determine the laws of the syllogism matrices that cause linguistic shock,

2. determining the time level to recall the appropriate response after a linguistic shock and

3. applying the laws derived from an experimental linguistic approach to reveal the effectiveness of these laws in enhancing the linguistic repartee level.

In dealing with the first issue, I and three of my students collected and analysed numerous sharp rejoinders (examples were obtained from Matthias, 2008; Ibn Abi Awn, 1996; Al-Obbi, 2004; Al-Zamkshari, 1991 \& Al-Abshihi, 1986) from different cultures. The analysis was directed at the logical linguistic structure of these sharp rejoinders, and this effort is considered an attempt in the linguistic matrix analysis and detection of the 
correlations systems in these linguistic matrices. Hence, I analysed sharp rejoinders in terms of the logical linguistic propositions. I called these linguistic propositions 'matrices', which are inter-linked by the laws of correlative syllogism. Accordingly, I called them syllogism matrices. This analytical process involving sharp rejoinders leads us to understand the systems of these matrices and their laws, thereby enabling the development of mechanisms that can enhance the linguistic repartee level.

We firstly decide that enhancing the linguistic repartee level requires taking care of the brain operations and patterns of thinking (Mullen 1995, p. 2), and occurs owing to the development of the appropriate techniques for linguistic thinking. This development is achieved by raising the awareness of the linguistic systems that we use and through continuous practice that converts this awareness into aptitude by raising the performance and speed levels in intellectual linguistic processing.

The syllogism matrix laws in sharp rejoinders will be displayed. A sharp rejoinder is a linguistic logical argumentative measure (syllogism) consisting of at least two matrices, namely, allegation matrix (AM) and response matrix (RM). Their correlation evidence (CE) will also be displayed.

AM is the linguistic unit that occurs because of linguistic shock and is the starting point for RM. The correlation of these matrices leads to linguistic shock. Thus, AM is a linguistic unit that includes an allegation. This matrix is divided into the following three types.

1. Judgmental (JU) includes a judgment of coupling two things. For example, somebody said to a blind man, 'You are as your horde, become ill usually in your eyesight'. The blind man answered, 'And you are as your horde, become ill usually in your insight (i.e. discernment)'. AM in this example is the former and evidently includes a judgment of coupling two things.

2. Conditional (CO) links two matrices to form one matrix, thereby becoming two submatrices after analysis. For example, a woman said to Churchill, 'If you were my husband, then I'd put poison in your coffee'. Churchill answered, 'If you were my wife, then I'd drink it'. AM in this example is 'If you were my husband, then I'd put poison in your coffee'. Hence, the two matrices are linked.

3. Imperative (IM) contains a request either in external reality (ER) or intellectual reality (IR) (i.e. asking about unknown things). An example of ER is as follows: 'Have you written on the cake the phrase, "with sincere congratulations"?' The reply is as follows: 'Well, bring me a typewriter'. AM in this example is 'Have you written on the cake...' and it is imperative (ER). The example for IR is as follows: 'Why are your teeth yellow?' The reply is as follows: 'I work in the Postal Service'. AM in this example is as follows: 'Why are your teeth yellow' and it is imperative (IR).

$\mathrm{RM}$ is a linguistic unit that links with $\mathrm{AM}$ and is the reply to the allegation in the former. The relationship between the two matrices creates an argumentative context, and the types of RM are the same with the AM types. Accordingly, the matrices may be similar in type, differ partially, or differ entirely as follows:

$\mathrm{AM} \rightarrow \mathrm{RM}$ : You spend a lot of money... Reply: I have a printer. (Similarity)

$\mathrm{AM} \rightarrow \mathrm{RM}:$ A woman asked a well-known doctor: 'Are you really a veterinarian?' $\mathrm{He}$ replied: 'Come tomorrow to treat you'. (Partial difference)

$\mathrm{AM} \rightarrow \mathrm{RM}$ : A man asked Bernard Shaw: 'Is not the cook better for people than the literary?' He answered: 'Dogs believe this'. (Entirely difference). 
$\mathrm{CE}$ is about systems that enable a sharp rejoinder to produce linguistic shock. By understanding $\mathrm{CE}$, we can produce an appropriate response to a sharp rejoinder, which is a disclosure of the relationship between AM and RM. I extrapolated these rules and relations by studying many sharp rejoinders. Hence, I will shorten the representation. I will likewise present CE.

$J U$

In the JU matrix, RM in a sharp rejoinder may be identical to or does not match AM in accordance with the following laws.

Firstly - Similarity: The maker of a sharp rejoinder links RM to AM and the reality. If the victim attempts to deny RM, he will be against either AM. Therefore, contradiction (i.e. against reality) and lie occurs. This correlation causes a linguistic shock.

Example of the first correlation/ man: I see you a lot on every road, man replied. This means: also, I see you a lot.

The analysis

$\mathrm{AM}(\mathrm{JU})+\mathrm{RM}(\mathrm{JU}) \Rightarrow \mathrm{AM} \rightarrow \mathrm{RM}$

$\mathrm{RM} \hookrightarrow($ related with AM)

$(\mathrm{RM})$ Denial $=$ Contradiction

Result: Linguistic shock

Example of the second correlation: A short man told his colleagues at work: 'I'll go to the manager, and I'll tell him our decision to his face'. A colleague said to him: 'And then, I will lift you up'.

The analysis

$\mathrm{AM}(\mathrm{JU})+\mathrm{RM}(\mathrm{JU}) \Rightarrow \mathrm{AM} \rightarrow \mathrm{RM}$

$\mathrm{RM} \hookrightarrow$ (related with the reality). He is short.

$(\mathrm{RM})$ Denial $=$ lie

Result: Linguistic shock

The relationship with reality is evident. However, what are the types of relationships between AM and RM? I can divide these relationships into two main parts.

-Relation of Negation: The relation between AM and RM is a negation. Example: A woman: All beautiful things borrowed the beauty from my face. A man: Yes, and they did not bring it back. In this example, RM is related with AM, and the negation of RM leads to contradiction. The relationship between them is a negation.

-Relationship of Explanation: RM is based on AM, but RM provides an explanation for AM. This relationship is considered a tacit negation not found in linguistic units. Example: A man said to Bernard Shaw: I am better than you, you write about money, whilst I write about honor. Bernard Shaw said yes, everyone writes what he lacks. In this example, RM is related with AM, and includes an explanation of AM and a tacit negation of the AM tenor. Another example: A man said to a man: It is nice to praise George, whilst he dispraises you. $\mathrm{He}$ replied: It seems that both of us are wrong. In this example, RM is related with AM, and includes the explanation of AM and a tacit negation of the AM tenor.

Secondly - Transfer to IM: AM is JU and RM is IM. The correlation here is connect $\mathrm{RM}$ with the part of AM content. Example: He said to him: You stand in the wrong place. He 
replied: Do you want me to lie down in it? Note how he connected RM with a 'stand', which is part of the AM content, whilst it did not connect it with 'standing in the wrong place', which is the full AM content.

Thirdly - Transfer to CO: AM is JU and RM is CO. In this case, RM is a result of AM. Example: He said to her: You are very thin. She replied: If I ride a bike, then I will be more lissome and faster. Moreover, if I buy clothes, then I do not feel disappointed.

$I M$

In the IM matrix, RM in a sharp rejoinder may be identical to or does not match AM, in accordance with the following laws.

Firstly - Similarity: In this type, RM does not cause a linguistic shock unless it makes AM against reality. For example, a journalist asks a politician: What are the most important decisions of your closed meeting? He replied: Is it not a closed meeting? In this example, RM is similar to AM in type, and RM made AM in this example against the reality (i.e. closed meeting). This correlation caused a linguistic shock.

Secondly - Differential transition: The types are as follows.

1. Partial transition: transition from IR to ER and vice versa. However, this transition is within the matrix itself (IM). Example: Ask him: 'What would I do if the doctor told me that "You will not live more than two months?" He answered him: Change your doctor immediately.

2. Transition to JU. Example: Where are your mistakes? Answer: In the drawer (Entirely transition).

3. Transition to CO. Example: Which of your friends is a bore? Answer: If you look around, then you will see him (Entirely transition).

In the matrices $(1+2)$, it is difficult to make a linguistic shock only with regard to context collapse. That is, whenever RM veers away from the AM context, a sharp rejoinder will be considerably profound. This reply is called answer by nonsense (Matthias, 2008: 31). However, matrix (3) generally relies on the context. That is, order to cause a linguistic shock. Thus, the tenor of the respondents' answer of 'If you look around, then you will see him' depends on the current context. That is, no one in the place except the claimer (i.e. AM maker) and contexts are numerous according to AM.

$\mathrm{CO}$

The CO matrix consists of two interconnected parts: the previous condition and the predicate (i.e. next) (Al-Ghazali 1961, 110). Therefore, its laws are presented as follows.

Firstly - Similarity: RM is similar to AM and the correlation that produces linguistic shock is presented as follows.

1. Correlation with AM, as in the case of JU. Example: Churchill's previous example. She said to him: 'If you were my husband, then I'd put poison in your coffee'. He replied: 'If you were my wife, then I'd drink it'. RM with its two parts (i.e. previous condition and predicate links with AM with its two parts, and the RM denial causes the contradiction.

2. RM in this case resembles AM but contrary to the second part content (i.e. predicate or next). Example: A man came from afar, one of those sitting said to him: When you came from afar, I thought you are a woman. The man replied: When I came from afar, I thought you are a man. 
Analysis:

- AM: When you came from afar, I thought you are a woman.

Previous condition: You came from afar.

Predicate: I thought you are a woman.

- RM: When I came from afar, I thought you are a man.

Previous condition: I came from afar.

Predicate: I thought you are a man.

Evidently, the predicate's content in RM is in contrast with that in AM. These similarities and contradictions cause a linguistic shock.

Secondly - Differential transition to JU. In this case, AM is CO and RM is JU. Thereafter, RM is considered the result of AM. Example: He said to him: If you wore a black shoe would have been nicer. He replied: I forgot that you do not look up.

Thirdly - Differential transition to IM. In this case, AM is CO and RM is IM. The transition in this matrix is divided into two parts as follows.

1. Differential transition to the IR matrix. The correlation is achieved contrary to the previous condition (i.e. first part) in AM. Example: He said: If it rains outside, then I will wear a coat. He replied: Is it usually raining inside?

2. Differential transition to the ER matrix. In this case, RM is an explanation of the predicate (i.e. second part) in AM. Example: A singer said to another: When you sing, even dogs evade. He replied: You have to run behind them because they are looking for your sound.

\section{EXPERIMENTAL APPROACH}

The following core question remains: Does understanding the rules enhance the linguistic repartee level? To answer this question, we firstly need to determine the time that a linguistic shock occurs after a sharp rejoinder, which could be relatively difficult because of many overlapping factors. However, a cut-off limit can be considered to measure this period and achieve a wide range of sharp rejoinder was presented to a group of my students $(n=100)$. For the characteristics of the chosen sample, all of them are my students, Arabic speaking and in the 20-22 years age range. The time spent for the first answer was calculated as a criterion for accepting the answer. A Survey Monkey-questionnaire of one question was developed and distributed by three of my students to over 1000 respondents to measure the time required by a respondent to provide an appropriate answer. A total of 780 respondents answered the question. All of them Arabic- speaking and of different age groups. Given the lowest time answer is 5-30 $\mathrm{min}, 5 \mathrm{~min}$ was considered a criterion of answer pace. The experiment began by presenting a wide range of sharp rejoinders to the respondents before investigating the rules of the syllogism matrices. The results were not satisfactory.
$60 \%$
They could not answer
$10 \%$
$20 \%$
They created acceptable answers at five minutes
$10 \%$
They created acceptable answers after 10 minutes
They put unacceptable answers after 6 minutes

The rules of the syllogism matrices were explained to the intended students and applied on many models of the sharp rejoinders. The method of application was initially based on the matrix type. Thereafter we began to apply a different model to all the matrices 
with no particular order. I likewise studied the index of speed and acceptability of the replies. I considered the acceptance criterion from CE. The speed of the students in replying was varied. The best speed and acceptability levels are as follows.

TABLE 2. Speed and Acceptability Levels

\begin{tabular}{ccc}
\hline Percentage & Time & Type of reply \\
\hline $63 \%$ & 20 second - minute & Acceptable \\
$12 \%$ & $2-4$ minutes & Acceptable \\
$12 \%$ & 1 minute & Unacceptable \\
$6 \%$ & 10 minutes & Acceptable \\
$7 \%$ & They could not answer & - \\
\hline
\end{tabular}

Although the indices of these percentages are merely an approximation and surrounded by many complex circumstances, such indices are an explicit indicator of the application of the effectiveness of the syllogism matrix law in promoting the ability to produce an acceptable reply to sharp rejoinders and avoid the problem of linguistic shock. This result indicates the effectiveness of these matrices in the development of a linguistic repartee.

\section{CONCLUSION}

My hypothesis was that sharp rejoinders contain syllogism matrices, which are linguistic and logical units forming the systems of sharp rejoinders. Presumably, the comprehension of these units leads to improvement in the linguistic repartee level. This development is demonstrated by increasing the capacity of creating an acceptable reply in a short time, which the current study attempted to prove through analytical and experimental methods. The following conclusions are drawn.

1. The central cause of linguistic shock in a sharp rejoinder is the system of $\mathrm{CE}$ in the linguistic matrices that form the sharp rejoinders.

2. The comprehension of these matrix systems improves the level of linguistic repartee.

3. Developing these rules and systems into courses and teaching them to students would be beneficial to improve their linguistic repartee.

4. The syllogism matrices can be conceded a system and competence in the mental constructs of speakers if they practice them consciously.

5. I suggest classifying linguistic shock on the list of interlocutory language disorders.

\section{ACKNOWLEDGEMENT}

This Work was supported by UAE University, Grant Code: G00002853.

\section{REFERENCES}

Al-Abshihi, M. (1986). AL-Mostaţraf, $2^{\text {nd }}$ ed. Unearthed by: Mufeed Mohammed. Beirut: Dar AL-Kotob ALIlmiyah.

Albrecht, K. (1980). Brain Power. New York: A Fireside book.

Bandler, R. \& Grinder, J. (1975). The Structure of Magic. A Book about Language and Therapy. USA: Science and Behavior Books.

Bornat, R. (2017). Proof and Disproof in Formal Logic. UK: Oxford University Press.

Brabandere, L. \& Iny, A. (2013). Thinking in New Boxes. New York: Random House.

Chambers, W. \& Robert. (1833). Promptitude, Chamberss' Edinburgh Journal, Vol. 12 (99), 369- 371. 
Dane, E. \& Pratt, M. (2007). Exploring Intuition and Its Role in Managerial Decision Making. Academy of Management Review, Vol. 32(1), 33-54.

De bono, E. (1967). The Use of Lateral Thinking. England: Penguin books.

Dennett, D. (2013). Intuition Pumps and Other Tools for Thinking. New York: W.W. Norton and Company.

Elder, L. \& Paul, R. (2013). 30 Days to Better Thinking and Better Living with Critical Thinking. New Jersey: Pearson Education.

Gee, J. (1999). Intuition: Awakening Your Inner Guide. Boston: Weiser Books.

Al-Ghazali, M. (1961). M'yâr AL-'elm, Unearthed by Suleiman Donia. Cairo: Dar AL- Ma'arif.

Henden, G. (2004). Intuition and its Role in Strategic Thinking, Series of Dissertations 4/2004. Oslo: BI Norwegian School of Management.

Hung, B. (2019), A Cognitive Linguistic Approach to Teaching English Idioms to EFL Students: Experimental Results. 3L: The Southeast Asian Journal of English Language Studies. Vol. 25(2), 113-126.

Ibn Abi Awn, E. (1996). The Sharp Rejoinders. Unearthed by Mai Yousef. Cairo: Ain for studies and research, Cairo.

Kahneman, D. (2011). Thinking Fast and Slow. New York: Farrar Straus and Giroux.

Lieberman, M. (2000). Intuition: A Social Cognitive Neuroscience Approach. American psychological association. Vol. l (1), 109-137.

Lufityanto, G., Donkin, Ch. \& Pearson, J. (2016). Measuring Intuition: Nonconscious Emotional Information Boosts Decision Accuracy and Confidence. SAGE: Psychological Science OnlineFirst.

Mullen, J. (1995). Hard Thinking, The Reintroduction of Logic into Everyday Life. New York: Rowman and littlefield publishers.

Al-Obbi, M. (2004). Nàther AL-Dur, $1^{\text {st }}$ ed. Unearthed by: Khaled Mahfouz. Beirut: Dar AL-Kotob ALIlmiyah.

Matthias, P. (2008). Nicht auf den Mund gefallen, translate to Arabic: Elias Hajõj. AL-Riyadh: AL- Obeikan.

Simone, W. (2014). First Intelligence: Using the Science and Spirit of Intuition. California: New World Library.

Al-Zabin, E. (2018). Linguistic formation of recipient's intellect: An interdisciplinary study in rules of contentedness formulation. Dirasat Journal, The University of Jordan, Acceptable search for publication.

AL-Zabin, E. (2014). Linguistic Thought of the Rationalist Muslim Scholars, $1^{\text {st }}$ ed. Amman: Dar AL-Noor.

Al-Zamkshari, M. (1991). Rabee' $A L-A b r a r, 1^{\text {st }}$ ed. Beirut: Al-A 'lami Fondation. 